\title{
Analysis of the Game of the Content Subject in the Tri-networks Integration
}

\author{
Ji-Hua XIE ${ }^{1, a}$, Qian ZHANG ${ }^{2, b, *}$ \\ 12 School of Political Science and Public Administration, University of Electronic Science and \\ Technology of China, Chengdu, P.R. China, 611731 \\ ajhxie@uestc.edu.cn, bzhangqian_aquarius@163.com \\ * Qian ZHANG
}

Keywords: Tri-networks integration, the content subject, the content provider, Game theory reflects.

\begin{abstract}
With the rapid development of optical fiber communication industry, the integration of China's Tri-networks is being promoted constantly and deeply. 'One-to-many', a new mode which the content provider offers the content subject to telecommunication network, broadcasting television network and Internet changes the traditional 'Many-to-one' mode. This thesis is based on the game theory analyses the influence of the two kinds of modes on the content subject behavior decision effects and economic benefits. Finally, the content subject economic benefits can be maximized under the new mode.
\end{abstract}

\section{Introduction}

The integration of telecommunication network, broadcasting television network and Internet is called Tri-networks integration, which the Internet is the key. From the perspective of implementation, the Tri-networks integration not only refers to the same service and content can be provided both in the broadcasting television network, but also in the telecommunication network. Additionally, it includes the broadcasting television network and the telecommunication network to achieve business integration [1].

In January 13th, 2010, the State Council declared to accelerate the integration of telecommunication network, broadcasting television network and Internet in 2012, until the end of 2015. This will be another major opportunity for China's optical fiber communication industry [2].

The promotion of the Tri-networks integration changed the traditional 'Many-to-one' mode, the content subject to the broadcasting television network is replaced by the new 'One-to-many' mode, which contains the content subject to telecommunication network, broadcasting television network and Internet. In the past, if content providers wanted to put content products on the operators of the broadcasting television network, it is necessary to compete with industry peers and form a 'Many-to-one' mode. But now, the monopolistic status of operators is broken, the content providers can choose to put their content products in any platform of telecommunication network, broadcasting television network and Internet, or even multiple platforms.

Both of the new and old modes, the content subject will be influenced by the operators and competitors in the peer industry to make different behavioral decisions. If an appropriate decision is made, the benefit maximization will be realized in the decision-making mode. But if the decision is improper, it may lead to failure. How the content subject plays a game among the telecommunication operators, the broadcasting television operators and other competitors in the Tri-networks integration environment, making the right decision and maximizing the economic benefits are the important propositions.

\section{Application of Game Theory}

The decision-making situation can be called game when there are many decision-makers coexist, and pursue their respective goals separately, this decision-making situation can be called game. As 
we all know, 'game theory' is a theory that studies the decision-making and equilibrium problems of rational decision-makers when they collide with each other [3].

The classical Nash equilibrium concept and theorem in game theory (John Nash, 1950) lays the cornerstone of non-cooperative game theory. Game theory is divided into cooperative game theory and non-cooperative game theory. The difference between the two is mainly the interaction of people's behavior, the parties can reach a binding agreement. If there is a cooperative game, on the contrary, it is a non-cooperative game. Cooperative game theory tends to research on cooperation, emphasizing group rationality, efficiency, justice and fairness; non-cooperative game theory is biased to the research of competition, emphasizing individual rationality and individual optimal decision [4].

In the process of the Tri-networks integration, the content subject, telecommunication network, broadcasting television network and Internet are regarded as four participants, each stakeholders interacts with each other, and the interaction among them affects their thinking and action, and directly affects the result of the game [5].

\section{Establishment of Game Function of Two Modes}

\section{Traditional Mode: 'One-to-Many'}

In the past, the operators of radio and television were in a monopolistic position, and content subjects could only put their own content products to broadcast television operators. In the market, there will be two or more homogeneous content subject to compete with each other, when they put their content products on the radio and television operators, it formed a game. Broadcast and television operators choose the quality and price of content products, and the action of the content main body is to choose to produce the right content product and content product price expense, because they can only choose whether to put content product on broadcast television operator, payment function is profit.

Here, we assume that the content of the subject product is the same, the profit is $\boldsymbol{\pi}$, the yield is $\mathbf{y}$, the cost is $\mathbf{p}$, the profit function is:

The profit of the content subject $\left(\boldsymbol{\pi}_{\mathbf{0}}\right)=$ the income of the content subject $\left(\mathbf{y}_{\mathbf{0}}\right)$-The cost of the content subject (po).

The prerequisite for this formula is the successful cooperation between the content subject and the broadcasting television operators.

If cooperation fails, then $\boldsymbol{\pi}_{\mathbf{0}}=\mathbf{0}$;

However, because of the monopoly of broadcasting television operators and the competition of the subject of homogeneous content in the market, the growth of $\mathbf{p}_{\mathbf{0}}$ will lead to the decline of $\boldsymbol{\pi}_{\mathbf{0}}$. Therefore, in the traditional 'Many-to-one' mode, the content subject is difficult to achieve maximum profit.

\section{New Mode: 'Many-to-One'}

Since the 1970s, the rapid development of computer and information network technology has aroused the convergence of media, telecom and information services, and the Tri-networks integration has become a focus of attention. In our country, Tri-networks integration is not only the fusion of technical level, also includes the multi-level integration of business, market, laws and regulatory bodies, the core of which is not some kind of network eminence, but to exert the physical advantage of different networks, so that anyone can easily obtain any kind of information service through any kind of physical network [6].

In the case of the Tri-networks integration, the content subject can choose the any one of telecommunication network, broadcasting television network and Internet, and some of the Internet platform operators to put their own content products. The conflict here is the cost of both sides of the game. Both sides of the game are content subject and platform operator (telecommunication network, broadcasting television network and Internet), the platform operator chooses the price 
(how to price), the content main body chooses the platform, the income is the content main body's payment function.

Here we set the following variables: Profit $(\boldsymbol{\pi})$, revenue $(\mathbf{y})$, cost (platform operator price) (p), user amount $(\mathbf{n})$, proportional coefficient $(\boldsymbol{\alpha})$, game model function as follows Figure. 1:

\begin{tabular}{|c|c|c|}
\hline & Action Select & Payment Function (Profit) \\
\hline $\begin{array}{c}\text { Operator 1: } \\
\text { Broad-casting } \\
\text { television network }\end{array}$ & $\mathrm{p}_{1}$ & $\pi_{1}=\alpha_{1} \mathrm{p}_{1}-\mathrm{c}\left(\mathrm{n}_{1}\right)$ \\
\hline $\begin{array}{c}\text { Operator 2: } \\
\text { Telecommunication } \\
\text { network }\end{array}$ & $\mathrm{p}_{2}$ & $\pi_{2}=\alpha_{2} \mathrm{p}_{2}-\mathrm{c}\left(\mathrm{n}_{2}\right)$ \\
\hline $\begin{array}{c}\text { Operator 3: the } \\
\text { Internet }\end{array}$ & $\mathrm{p}_{3}$ & $\pi=\alpha_{3} \mathrm{p}_{3}-\mathrm{c}\left(\mathrm{n}_{3}\right)$ \\
\hline Content Subject & $\begin{array}{c}\sum \alpha_{\mathrm{i}} \mathrm{p}_{\mathrm{i}} \\
\left(\sum \alpha_{\mathrm{i}}=1\right)_{\mathrm{i}}\end{array}$ & $\begin{array}{c}\pi=\mathrm{y}\left(\sum \alpha_{\mathrm{i}} \mathrm{n}_{\mathrm{i}}\right) \\
-\sum \alpha_{\mathrm{i}} \mathrm{p}_{\mathrm{i}}\end{array}$ \\
\hline
\end{tabular}

Figure. 1: 'One-to-many' mode game model function

Here, we assume that the price of the platform operators is fixed, that is, the content subject is fixed. The content subject delivers their content products to the three operator platforms according to the proportion and the cost could be calculated by this proportion.

Among them, the profit is a function about the dissemination efficiently of the content, which is put by the content subject on the operators' platform (based on the proportion of content put by the subject on the three platforms to calculate the transmission efficiently). The cost is about the number of users, human costs, etc. Profit is a function of the difference between the income (the individual user's earnings multiplied by the total user) and the cost.

\section{Profit Comparisons between 'One-to-Many' and 'Many-to-One'}

Suppose the content subject to the platform operator's cost $\mathbf{p}$ is fixed, to compare the profit $\mathbf{p}_{\mathbf{i}}$ size, compares the income $\mathbf{y}$ the size to be able.

By economic theory, $\mathbf{Y}(\mathbf{x})$ is a two-time function on $\mathbf{x}$, or $\mathrm{y}(\mathrm{x})=(\mathrm{x}-\mathrm{b}) 2+\mathrm{c}$.

'Many-to-One' Mode:

$$
\begin{aligned}
& \pi_{0}=\left(\mathrm{A}_{1}+\mathrm{A}_{2}+\mathrm{A}_{3}\right)\left[-\left(\mathrm{p}-\mathrm{B}_{1}\right)^{2}+\mathrm{c}_{1}\right]-\left(\alpha_{1}+\alpha_{2}+\alpha_{3}\right) \mathrm{p} \\
& \left(\alpha_{1}+\alpha_{2}+\alpha_{3}=1\right)
\end{aligned}
$$

'One-to-Many' Mode:

$$
\begin{aligned}
& \pi=\alpha_{1}\left[-\left(p_{1}-B_{1}\right)^{2}+c_{1}\right]+\alpha_{2}\left[-\left(p_{2}-B_{2}\right)^{2}+c_{2}\right]+\alpha_{3}\left[-\left(p_{3}-B_{3}\right)^{2}+c_{3}\right]-\alpha_{1} p_{1}-\alpha_{2} p_{2}-\alpha_{3} p_{3} \\
& \left(p_{1}+p_{2}+p_{3}=p\right)
\end{aligned}
$$

Suppose cost $\mathrm{p}=100, \mathrm{p} 1=30, \mathrm{p} 2=20, \mathrm{p} 3=50$,

In the traditional 'many-to-one' mode, the profit $\pi_{0}$ has an extreme value, and in the current 'one-to-many' mode, the Profit $\left(\mathbf{p}_{\mathbf{i}}\right)$ has three extremes.

Obviously, in the case of a certain cost, the current 'one-to-many' mode is the most likely to maximize profits.

\section{Conclusion}

Through the above-mentioned content on the two model of game model analysis and comparison, as well as the final profit function comparison, that in the case of a certain cost, the current 'one-to-many' mode than the traditional 'many-to-one' mode to obtain greater profits. Therefore, it 
also explains the necessity of speeding up the process of Tri-networks integration from the angle of the content subject game.

\section{References:}

[1] Yi Wen. Discussion on the popularization of Tri-networks integration and the reform of broadcasting television media system [J]. China Digital Cable TV, 2015 (10)

[2] Tibin Liu, Yingjin Lu, Lu Jiao. The benefits distribution of Tri-networks convergence Chain [J]. Theoretical Economics Letters, 2011, 1, 73-80

[3] Pindyek RS, Rubinfeld DL, Zhang June and other translation. Microeconomics (third edition) [M]. Beijing: Renmin University Press, 1997:5,301,531

[4] Bai Shumei. Analysis of urban industrial economy based on multidimensional game model [D]. Guangzhou: Guangdong University of Technology, 2008

[5] Xu Nan. The game of total win: Tri-networks integration in the context of telecommunications network, radio and television network, internet cooperation [J]. News dissemination, 2012

[6] Li, Jian, Zengjianqiu. Current situation and development strategy of triple-network fusion [J]. China Communications, 2010 